\title{
О ПРЯМОМ ПРЕОБРАЗОВАНИИ ХИМИЧЕСКОЙ ЭНЕРГИИ ЭНЕРГЕТИЧЕСКИХ КОНДЕНСИРОВАННЫХ СИСТЕМ В ЭЛЕКТРИЧЕСКУЮ В РЕЖИМЕ ГОРЕНИЯ
}

\begin{abstract}
В.В. Просянюк ${ }^{1}$, И.С. Суворов ${ }^{1}$, Н.В. Прудников ${ }^{2}$
${ }^{1}$ Акционерное общество «Федеральный научно-производственный центр «НИИ прикладной химии» (АО «ФНПЦ НИИ прикладной химии»), ул. Акад. Силина, д. 3, Сергиев Посад Московская обл., Российская Федерация, 141313

E-mail: vvp501210@yandex.ru,vvpotd4@niiph.com

${ }^{2}$ ФГБУН Межведомственный центр аналитических исследований в области физики, химии и биологии при Президиуме Российской академии наук (МЦАИ РАН), ул. Профсоюзная, д. 65, стр. 6, Москва, Российская Федерация, 117342

Резервные источники тока в виде батарей высокотемпературных гальванических элементов (ВГЭ), электроды которых выполнены из разнородных малогазовых энергетических конденсированных систем (ЭКС), широко применяют для задействования и питания приборов и устройств различного назначения в экстремальных условиях. Прямое преобразование химической энергии ЭКС в электрическую энергию в режиме горения является новым направлением высокотемпературной электрохимии. Результаты исследований безгазового горения тонких многослойных ВГЭ с легкоплавким инертным компонентом (электролитом) представляют теоретический и практический интерес для высокотемпературной электрохимии и получения слоевых композиционных материалов различного назначения методом самораспространяющегося высокотемпературного синтеза (СВC).
\end{abstract}

Ключевые слова: энергетические конденсированные системы, высокотемпературный гальванический элемент, резервный источник тока

\section{DIRECT CHEMICAL ENERGY CONVERSION OF POWER-CONDENSED SYSTEMS INTO ELEC- TRIC ENERGY IN COMBUSTION MODE}

\author{
V.V. Prosyanyuk ${ }^{1}$, I.S. Suvorov ${ }^{1}$, N.V. Prudnikov ${ }^{2}$
}

${ }^{1}$ Scientific Research Institute of Applied Chemistry. Akademika Silina Street, 3, Sergiev Posad, Moscow Region, Russian Federation, 141313

E-mail: vvp501210@yandex.ru,vvpotd4@niiph.com

${ }^{2}$ Federal State State-financed Institution of Sciences Interdepartmental Center of Analytic Studies in the Sphere of Physics, Chemistry and Biology under Presidium of Russian Academy of Sciences (ICAS RAS), 65 Trade Union Street, p. 6, Moscow, Russian Federation, 117342

Reserve current supplies like high-temperature galvanic cell battaries $(H G C)$, which electrodes consist of different low-gas power-condenced compositions (PCC) are widely used for inithiation and powering units and different devices in extreme circumstances. Direct chemical energy conversion of PCC into electric energy in combustion mode is a new direction of high-temperature electrochemistry. Researchment results low-gas combustion of multy-layer HGC with low-melting inert component have a theoretical and practical interest for high-temperature electrochemistry and a practical interest for self-propagating high-temperature synthesis (SHS) of different-purposed layered composite materials.

Key words: power-condensed compositions, high-temperature galvanic cell, reserve current supply 
Для цитирования:

Просянюк В.В., Суворов И.С., Прудников Н.В. О прямом преобразовании химической энергии энергетических конденсированных систем в электрическую в режиме горения. Рос. хим. ж. (Ж. Рос. хим. об-ва). 2021. T. LXV. № 3. C. $67-71$

For citation:

Prosyanyuk V.V., Suvorov I.S., Prudnikov N.V. Direct chemical energy conversion of power-condensed systems into electric energy in combustion mode. Ros. Khim. Zh. 2021. V. 65. N 3. P. 67-71

\section{ВВЕДЕНИЕ}

Анализ отечественной и зарубежной патентной и научно-технической литературы показывает, что сохраняется устойчивый интерес к улучшению и стабилизации характеристик резервных источников тока, т.к. они во многом определяют технический уровень аппаратуры, а также возможность совершенствования, стоимость и конкурентоспособность объектов применения. Эта проблема в Российской Федерации и за рубежом была и остается одной из самых актуальных [1-3].

\section{РЕЗУЛЬТАТЫ И ИХ ОБСУЖДЕНИЕ}

Прямое преобразование химической энергии энергетических композиций (ЭКС) в электрическую энергию может быть осуществлено при сгорании тонких многослойных композиций, выполняющих роль высокотемпературных гальванических элементов (ВГЭ), безгазовое горение которых сопровождается протеканием электрохимических процессов. Поэтому создание нового поколения миниатюрных резервных (автономных) источников тока (батарей ВГЭ) требует решения проблем, связанных с безгазовым горением, высокотемпературной электрохимией и самораспространяющимся высокотемпературным синтезом (СBC) многослойных композиционных материалов [4-7].

В связи с возможностью применения средств автономной электроэнергетики на основе малогазовых ЭКС в интересах обороны и безопасности страны необходимо их совершенствование. Ведётся поиск новых, более совершенных рецептур электродов, электролитных составов, нагревательных смесей, теплоизоляционных материалов, методов задействования, конструкций батарей и т.д. Обязательным требованием является способность надёжно функционировать при экстремальных внешних воздействиях.

Источники тока на основе малогазовых ЭКС представляют собой наборы (батареи) ВГЭ толщиной $\sim 1$ мм, при сгорании которых происходит генерирование электрического тока. Они в 3 4 раза дешевле термохимических источников тока с подобными характеристиками, а их параметры не зависят от пространственной ориентации, разрежения, избыточного давления, транспортных и эксплуатационных механических перегрузок, электромагнитных излучений, геометрической формы, не требуют регламентных проверок и обслуживания при температуре хранения и эксплуатации от минус 60 до $85{ }^{\circ} \mathrm{C}$. и т.д. Их приводят в действие (активируют) любыми электрическими и механическими средствами инициирования, продуктами сгорания, контактным нагревом и т.д. Зарубежные аналоги батарей ВГЭ не выявлены.

В зависимости от назначения они могут быть выполнены в герметичном или разгерметизирующемся корпусе после задействования. В первом случае процессы протекают в условиях повышенного давления за счёт газов, выделяющихся при сгорании. Во втором случае сгорание и генерирование тока может происходить при нормальных условиях, или при разрежении (в составе негерметичных высотных изделий). Параметры источников тока и их стабильность обеспечены, прежде всего, рецептурой ЭКС и конструктивными схемами ВГЭ и их батарей.

Эффективность резервных источников тока на основе ЭКС определяется высокой вероятностью воспламенения и сгорания ВГЭ в условиях интенсивного отвода тепла из зоны горения (между металлическими токоотводами) в экстремальных условиях. Их прочность достаточна для размещения батарей внутри изделий без собственного корпуса. Это позволяет использовать с максимальной полнотой свободный объём аппаратуры современных и перспективных потребителей электрической энергии. Особенность этих источников тока в том, что генерирование электрического тока происходит после сгорания ВГЭ, которые сохраняют форму и размеры исходного образца. Фторид лития и фторидные эвтектики на его основе (электролитный материал), являются диэлектриками при нормальных условиях, что обеспечивает термодинамическую устойчивость электрохимических систем (отсутствие саморазряда) и длительный гарантийный срок изделий ( $\geq 25$ лет). Их можно использовать как по прямому назначению для работы в режиме ожидания, так и встраивать в автономные управляющие и информационно-энергетические системы [8]. 
В нашей работе [9] экспериментально установлено, что при сгорании тонких ВГЭ на основе циркония и оксида меди в воздухе генерирование электрического тока происходит после плавления электролитного материала в зоне горения до кристаллизации электролитного расплава. При последовательном соединении ВГЭ напряжение увеличивается пропорционально числу ячеек. В процессе горения ВГЭ происходит капиллярное пропитывание электродов расплавом фторидного электролита.

Полнота превращения химической энергии в электрическую и длительность работы батареи ВГЭ определяются, прежде всего, конструкцией ВГЭ. Обязательными условиями являются исключение электронного контакта между продуктами сгорания электродов, наличие в них активных материалов, минимальная температура плавления электролита, оптимальная калорийность ВГЭ, качество тепловой изоляции и т.д. Следует отметить, что исследования, разработка и производство резервных источников тока направлены не на получение дешевой электроэнергии, а для гарантированного автономного энергоснабжения объектов, стоимость которых находится вне экономических расчетов.

Увеличению полноты превращения химической энергии ВГЭ в электрическую энергию способствуют:

- уменьшение объема газообразных продуктов сгорания за счет применения компонентов высокой чистоты (в первую очередь малогазового циркония) и удаления воды из всех элементов и материалов, контактирующих с ВГЭ. Важность снижения объема газообразных продуктов в том, что они фильтруются через ВГЭ, создавая избыточное давление, которое может вызвать диспергирование и привести к замыканиям (подкороткам), увеличению пористости, ухудшению качества контакта активных электродных материалов с расплавленным электролитом и т.д.;

- сохранение целостности и электропроводности металлических фольговых токоотводов между ВГЭ. Наиболее вероятно их разрушение (проплавление) в центре набора. При этом анодный и катодный элементы соседних ячеек взаимодействуют между собой, выделяя только тепло, что увеличивает перегрев, нецелевое расходование активных электродных компонентов и снижение электрических характеристик;

- исключение возможности образования электропроводных продуктов сгорания воспламенительных элементов, расположенных на боковой поверхности набора ВГЭ;
- уменьшение внутреннего сопротивления каждой ВГЭ и их батарей уплотнением (опрессовкой) ячеек и всего набора перед герметизацией корпуса. Применением в электрической цепи материалов с минимальным электрическим сопротивлением, не образующих при работе диэлектриков;

- максимальная длительность генерирования электрического тока. Этот показатель определяется, прежде всего, временем поддержания рабочего диапазона температур в каждой из ВГЭ. Нижней границей является температура плавления электролита. Во время разряда при постоянной температуре внутреннее сопротивление устройства растет вследствие протекания электрохимических и чисто химических процессов (тем быстрее, чем больше разрядный ток). Как правило, оптимальный рабочий диапазон температур зависит от плотности тока и довольно узок.

Отмечено, что в замкнутом объеме и при повышенном атмосферном давлении уменьшаются времена работы и максимальные значения напряжения батарей ВГЭ. Это обусловлено более быстрой анодной пассивацией, т.к. в этих условиях увеличивается скорость окисления тонкодисперсного циркония в аноде.

Представляют теоретический и практический интерес новые технические решения, позволяющие минимизировать возможность не электрохимического окисления анодного материала в батареях ВГЭ. Например, замена анодных элементов из ЭКС фольговыми дисками из активного металла равной площади с ВГЭ, обеспечивает возможность генерирования электрического тока при контакте с электролитным расплавом.

Металл анодных элементов должен иметь максимально высокий электродный потенциал, минимальное электрическое сопротивление, быть химически стойким и физически стабильным при хранении изделий в течение $\geq 25$ лет при температуре от минус 60 до $85^{\circ} \mathrm{C}$, не плавиться при работе батарей ВГЭ. Этим требованиям соответствует циркониевая фольга. Разрядные кривые батарей ВГЭ с металлическими анодами приведены на рис. 1.

Как следует из рис. 1, нестабильность напряжения батареи с алюминиевым анодом обусловлена его плавлением, вытеканием расплава и замыканиями ячеек. Нержавеющая сталь имеет низкую электрохимическую активность, а батарея ВГЭ с циркониевой фольгой генерирует электрический ток более 80 c.

Теоретический и практический интерес представляет применение в качестве загустителей расплавленного электролита тугоплавких соедине- 
ний, обладающих свойствами твердых высокотемпературных электролитов. Например, диоксид циркония, стабилизированный оксидами кальция или магния, является диэлектриком при температуре от минус 60 до $200{ }^{\circ} \mathrm{C}$, а при температуре выше $500 \ldots 600{ }^{\circ} \mathrm{C}$ становится проводником. К подобным соединениям относятся твердые растворы замещения с разным зарядом ионов, дефицит заряда в которых компенсируется образованием дефектов противоположного знака (кислородными вакансиями). Наиболее высокая проводимость при $1000{ }^{\circ} \mathrm{C}$ у диоксида циркония, стабилизированного оксидом скандия $[10,11]$. Эти соединения термостойки и инертны по отношению к расплавленным солям, представляют теоретический и практический интерес для применения в резервных источниках тока.

Тонкодисперсные порошки полиалюминатов одновалентных металлов получили широкое применение в качестве загустителей электролитных материалов термохимических источников тока благодаря удачному сочетанию химических, керамических и электролитических характеристик, возможности широкого варьирования их свойств. Для этих соединений характерна достаточно высокая униполярная проводимость по однозарядным (щелочным) катионам, обусловленная примесным разупорядочением кристаллической решётки. Они могут быть применены в источниках тока на основе ЭКС.

Следует отметить возможность создания батарей гибких ВГЭ. Они могут быть адаптированы к конкретным геометрическим формам конструкционных элементов аппаратуры в объектах применения, в том числе без собственного корпуса. Внешний вид таких ВГЭ и их батареи приведены на рис. 2.

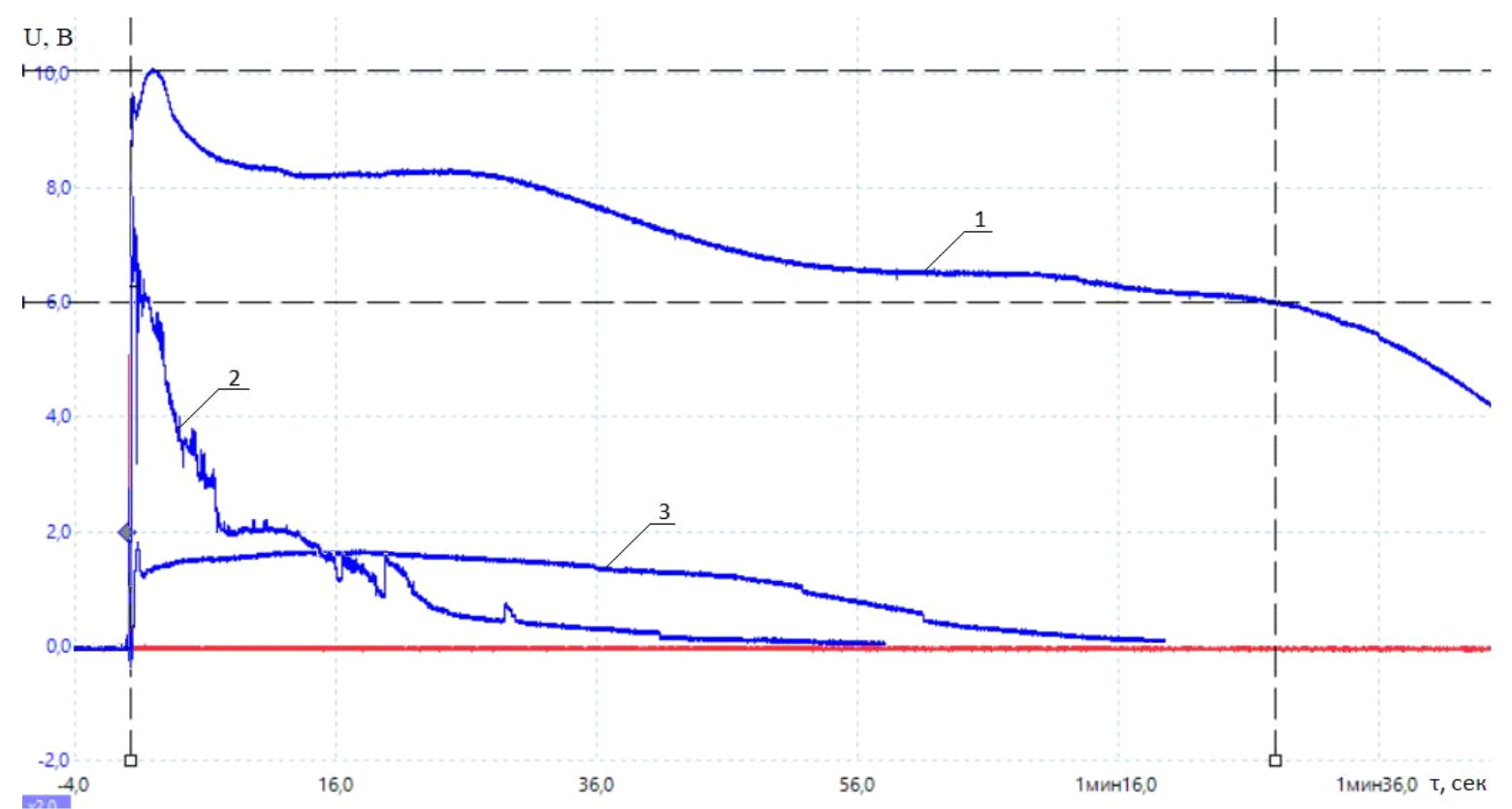

Рис. 1. Разрядные кривые батарей из 7 ВГЭ с металлическими анодами 1 - цирконий (0,03 мм); 2 - алюминий (0,05 мм); 3 - нержавеющая сталь (0,05 мм)

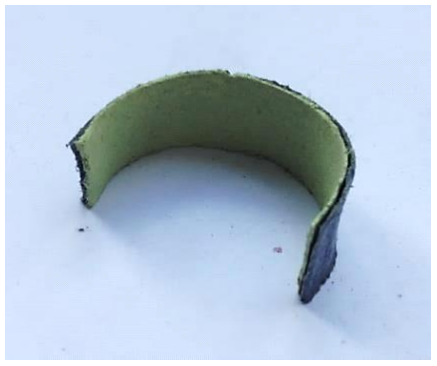

a)

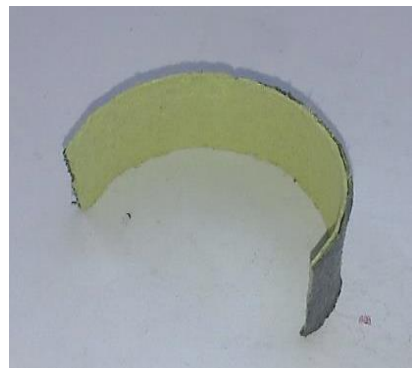

б)

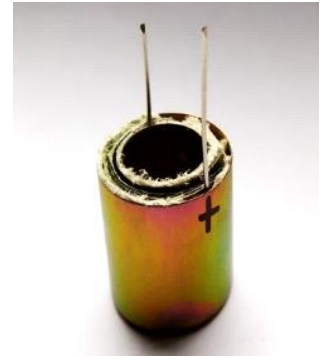

в)

Рис. 2. Внешний вид гибких ВГЭ и их батареи а) и б) - гибкие ВГЭ; в) - батарея гибких ВГЭ 


\section{ВЫВОДЫ}

Источники тока на основе ВГЭ из малогазовых ЭКС предназначены, прежде всего, для комплектации аппаратуры устройств, функционирующих в экстремальных условиях. Выявленные особенности воспламенения, горения и генерирования

\section{ЛИТЕРА Т УРА}

1. Афанасьев А.С., Болдырев М.А., Халютин С.П. Анализ номенклатуры химических источников тока, применяемой в объектах специального назначения. Электропитание. 2018. № 1. С. 40-49.

2. Bagotskii V.S., Skundin A.M., Volfkovich Yu.M. Electrochemical power sources: batteries, fuel cells, and supercapacitors. New Jersey: John Wiley \& Sons, 2015. 375 p.

3. Koch E.-C. Special materials in pyrotechnics VII: Pyrotechnics used in thermal batteries. Defense Technology. 2019. N. 15. P. 254-263.

4. Payne Ju. L., Giagloglou K., Carins G.M. In-situ Studies of High Temperature Thermal Batteries: a Perspective. Frontiers in Energy Research. 2018. V. 6. P. 1-6.

5. Просянюк В. В., Суворов И. С., Гильберт С.В., Сигейкин Г.И, Куликов А.В. Электрохимические системы резервных источников тока на основе энергетических конденсированных систем. Рос. хим. ж. 2016. Т. 60. № 3. С. 10-19.

6. Вагонов С.Н., Просянюк В.В., Суворов И.С., С.В. Гильберт, Зюзина Д.С. Резервные источники тока на основе энергетических конденсированных систем. Итоги науки. Выпуск 21. Избранные труды Всероссийской конференции по проблемам новых технологий. М.: РАН. 2015. С. 94-117.

7. Просянюк В.В. Суворов И.С. Паршиков Б.Ю., Прудников $H . B$. К вопросу о миниатюрных источниках тока на основе энергетических конденсированных систем. Нано- и микросистемная техника. 2020. № 4. C. 220-227. DOI: 10.17587/nmst.22.220-227.

8. Вагонов С.Н., Просянюк В.В., Суворов И.С. Многофункциональные резервные гибридные источники питания. Итоги науки. Выпуск 30. Избранные труды Всероссийской конференции по проблемам новых технологий (глава 1). М.: РАН. 2017. С. 3-24.

9. Barinov V.Yu., Kovalev D.Yu., Vadchenko S.G., Golosova O.A., Prosyanyuk V.V., Suvorov I.S., Gilbert S.V. Direct Conversion of Chemical Energy into Electrical Energy in the Combustion of a Thin Three-Layer Charge. Combustion, Explosion, and Shock Waves. 2019. V. 55. N. 6. P. 678-685. DOI: $10.1134 /$ S0010508219060078.

10. Демиденко Л.М., Полонский Ю.А. Электропроводность огнеупорных материалов - М: Металлургия. 1985. 120 с.

11. Пшеничный Р.Н., Погоренко Ю.М., Омельчук А.А. Электропроводность твёрдых электролитов на основе сложных фторидов РЗЭ. Физическая химия и электрохимия расплавленных и твёрдых электролитов. Материалы 16 Российской конференции. Т. 1. Екатеринбург: Изд. Уральского ун-та. 2013. $422 \mathrm{c}$.

12. Прокофьев В.Г., Лапшин О.В., Смоляков В.К. Макрокинетика горения слоевых композиций с легкоплавким инертным слоем. Вестник Томского государственного университета. Математика и механика. 2018. № 52. С. 102-113.

13. Рогачев А.С., Мукасьян А.С. Горение для синтеза материалов: введение в структурную макрокинетику. - М.: Физматлит. 2012. 400 с.

14. Прокофьев В.Г., Смоляков В.К. Влияние плавления инертного компонента и растекания расплава на нестационарные режимы горения безгазовых систем. Физика горения и взрыва. 2018. Т. 54. № 1. С. 27-32. DOI: 10.15372/FGV 20180105. электрического тока ВГЭ позволяют полнее реализовать их потенциальные возможности. Особенности воспламенения и горения ВГЭ представляют теоретический и практический интерес для получения слоевых композиционных материалов различного назначения методом самораспространяющегося высокотемпературного синтеза [12-14].

\section{REFERENCES}

1. Afanasev A.S., Boldirev M.A., Halutin S.P. Special purpose objects chemical current supplies nomenclature analysis. Electricpower. 2018. N 1. P. 40-49.

2. Bagotskii V.S., Skundin A.M., Volfkovich Yu.M. Electrochemical power sources: batteries, fuel cells, and supercapacitors. New Jersey: John Wiley \& Sons, 2015. 375 p.

3. Koch E.-C. Special materials in pyrotechnics VII: Pyrotechnics used in thermal batteries. Defense Technology. 2019. N 15. P. 254-263.

4. Payne Ju. L., Giagloglou K., Carins G.M. In-situ Studies of High Temperature Thermal Batteries: a Perspective. Frontiers in Energy Research. 2018. V. 6. P. 1-6.

5. Prosyanyuk V.V., Suvorov I.S., Gilbert S.V., Sigeykin G.I., Kulikov A.V. Electric-chemical systems of reserve curent supplies by power-condensed compositions. Rus Chemical Journal. V. 60. N 3. P. 10-19.

6. Vagonov. S.N., Prosyanyuk V.V., Suvorov I.S., Gilbert S.V., Zuzina D.S. Reserve current supplies by power-condenced compositions. Sientific results. Publication 21. M.: RAS. 2015. P. 94-117.

7. Prosyanyuk V.V., Suvorov I.S., Parshikov B.U., Prudnikov N.V. On the question of miniature current supplies by powercondenced compositions. Nano- and microsistematical tecknica. 2020. N 4. P. 220-227. DOI: 10.17587/nmst.22.220-227.

8. Vagonov. S.N., Prosyanyuk V.V., Suvorov I.S. Manyfunctional hybryd reserve power supplies. Sientific results. Publication 30. M.: RAS. 2017. P. 3-24.

9. Barinov V.Yu., Kovalev D.Yu., Vadchenko S.G., Golosova O.A., Prosyanyuk V.V., Suvorov I.S., Gilbert S.V. Direct Conversion of Chemical Energy into Electrical Energy in the Combustion of a Thin Three-Layer Charge. Combustion, Explosion, and Shock Waves. 2019. V. 55. N 6. P. 678-685. DOI: $10.1134 / \mathrm{S} 0010508219060078$.

10. Dimidenco L.M., Polonsky U.A. Fireproof materials electrical conductivity. M.: Metallurgy. 1985. 120 p.

11. Pshenichnii R.N., Pogorenko U.M., Omelchuk A.A. Complex fluoride solid electrolites electrical conductivity. Phisical chemistry and electrochemistry of molten and solid electrolites. T. 1. - Ekaterinburg: Pub. Ural university. 2013. 422 p.

12. Prokofev V.G., Lapshin O.V., Smoljakov V.K. Layered composition with low-melting inert layer combastion macrokinetics. Tomsk state bulletin. Mathematics and mechanics. 2018. N 52. P. 102-113.

13. Rogachev A.S., Mukasjan A.S. Combustion for sinthesys: introduction in structure macrokinetics. M. PhithMathsLit. 2012. $400 \mathrm{p}$.

14. Prokofev V.G., Smoljakov V.K. Influence of inert component melting and flowing on non-stationary low-gas compositions combustion modes. Phisics of combustion and explosion. 2018. T. 54. N 1. P. 27-32. DOI: 10.15372/FGV 20180105.

Поступила в редакиию (Received) 01.08.2021

Принята к опубликованию (Accepted) 03.09.2021 